\title{
Study of a railway embankment reinforced with jute tassels
}

\author{
ANIRUDDHA SENGUPTA* and SUVADEEP DALAL \\ Department of Civil Engineering, Indian Institute of Technology Kharagpur, \\ Kharagpur 721302, India \\ e-mail: sengupta@ civil.iitkgp.ernet.in
}

MS received 28 February 2014; revised 30 July 2014; accepted 11 September 2014

\begin{abstract}
This paper presents the results of laboratory model tests and corresponding numerical analyses carried out on a model slope representing an actual railway embankment which failed on several occasions after overnight heavy rainfall. In the absence of any field data, the displacement behaviour and failure pattern of the model embankment slope are observed in the laboratory under fully saturated condition and under a static load at the crest simulating the actual rail loads. A study is also performed by reinforcing the slope with thin jute tassels of $1 \mathrm{~mm}$ diameter. The numerical simulation of the model tests is performed by a commercial program called FLAC. The responses of the model slope with and without jute tassels are observed in fully saturated condition. Significant improvement in deformation of the slope is observed both in the case of numerical analyses and laboratory experiments when jute tassels are utilized as a slope protection measure. The study indicates that the stability of the railway embankment can be improved significantly at low cost by reinforcing it with jute tassels.
\end{abstract}

Keywords. Embankment; models (physical); soil reinforcement; jute tassel; slope failures.

\section{Introduction}

Failure of both natural and man-made slopes causes extensive loss of human life and property. But there is no universally accepted method for prevention or correction of slope failure. Each slope failure is unique and has its own typical characteristics. The main factors that govern stabilization of slope are; (i) the geometry and the surface of the slope, (ii) the strength of the slope materials and (iii) groundwater conditions. Some of the common measures for the slope protection are (i) improvement of the slope geometry by changing (flattening) the slope angle, (ii) removal of weak and undesirable soils at the head, (iii) protecting the slope toe by putting some heavy materials (like rocks and boulders) at the toe, (iv) construction of a compound slope instead of a single slope and (v) providing surface and subsurface drainage. Besides the above

*For correspondence 
traditional methods, inserting piles and soil anchors on the slope (Ausilio et al 2001; Rowe \& Poulos 1979) have been also found to be effective ways to stabilize a slope.

However, there are many instances where these corrective measures are unable to ensure stability and in many places their use is difficult, especially in railway embankments due to restrictions, space limitations and excessive cost.

Grimshaw (1994), Yoon (1994), Hengchaovanich \& Nilaweera (1996) have shown that the roots of small plants like certain shrubs and grasses can act as very good soil reinforcements and planting them on the slopes can enhance stability of the slope. The use of the vetiver grass (Vetiveria zizanioides) to reduce soil erosion is becoming popular in many countries throughout the world. Because of high tensile strength of vetiver grass roots, they act like soil reinforcement cables to stabilize a slope.

The repeated failure of the railway embankment at a place called Malda in the state of West Bengal in India is the main focus of the present study. Figure 1a shows a cross section of the railway embankment. At least three major train accidents have occurred in the recent past causing loss of property and human life at this place. In all the cases, the accidents occurred after overnight continuous heavy rainfall. The investigating agencies have blamed them on the sudden subsidence of the embankment due to pore water pressure buildup within the embankment and its foundation (RDSO 1998, 2011). The site inspection in August 2012 by the authors revealed several gullies and wet areas on the slope of the embankment formed by the seepage of the rainwater. Figure $1 \mathrm{~b}$ shows one such rain water gully on the slope at the accident site. Considering the destructiveness of these sudden slope failures, it is decided to perform geo-mechanical modelling of the slope failure mechanisms occurring within the embankment to assess the effect of rainfall on the embankment and to estimate the hazard due to sudden subsidence. This kind of slope failure after prolonged and/or heavy rainfall is not very uncommon throughout the world and several cases have been reported in the literature (Fowze et al 2012; Au 1998; Fourie 1996). But only a very few solutions have been proposed at present on the topic. In the present case, based on Bishop's limit equilibrium method as well as finite element analyses, a $2 \mathrm{~m}$ wide rockfill stabilizing berm on the downstream slope and sheet pile cutoff wall near the toe of the embankment, as shown schematically in figure 2, is proposed as a possible mitigation measure. This remedial measure has been implemented at the places of past accidents but not throughout the whole susceptible area due to exorbitant cost associated with it and/or lack of fund. This has prompted a fresh look at a cheaper but effective alternative remedial measure to prevent embankment slope failures in saturated condition, like reinforcing the slopes with jute tassels which can be obtained from the paddy fields located on both sides of the railway tracks at Malda.

This paper presents the results of laboratory model tests and corresponding numerical simulation of the scaled model slope with and without jute reinforcements under fully saturated condition. The tassels of jute utilized in the model study are purchased from the local market.

\section{Description of the study site}

\subsection{Cross sectional profile of the embankment}

The surveyed profile of a typical cross-section of the embankment at Malda, which is chosen for this study, is shown in figure 3. The maximum height of the embankment is $4.4 \mathrm{~m}$. The average side slopes of the embankment are $2(\mathrm{H}): 1(\mathrm{~V})$. The average width of the crest is $6.7 \mathrm{~m}$. At several locations, shallow ponds exist about 1.5 to $2 \mathrm{~m}$ from the toe on both sides of the embankment. 


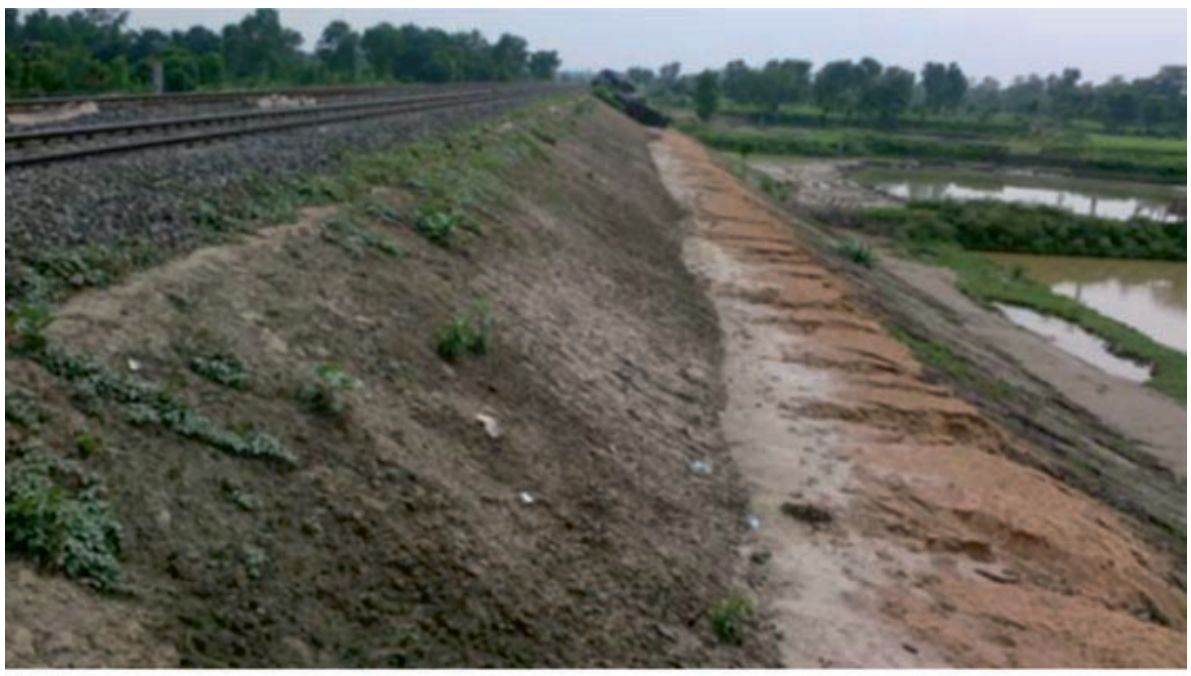

(a)

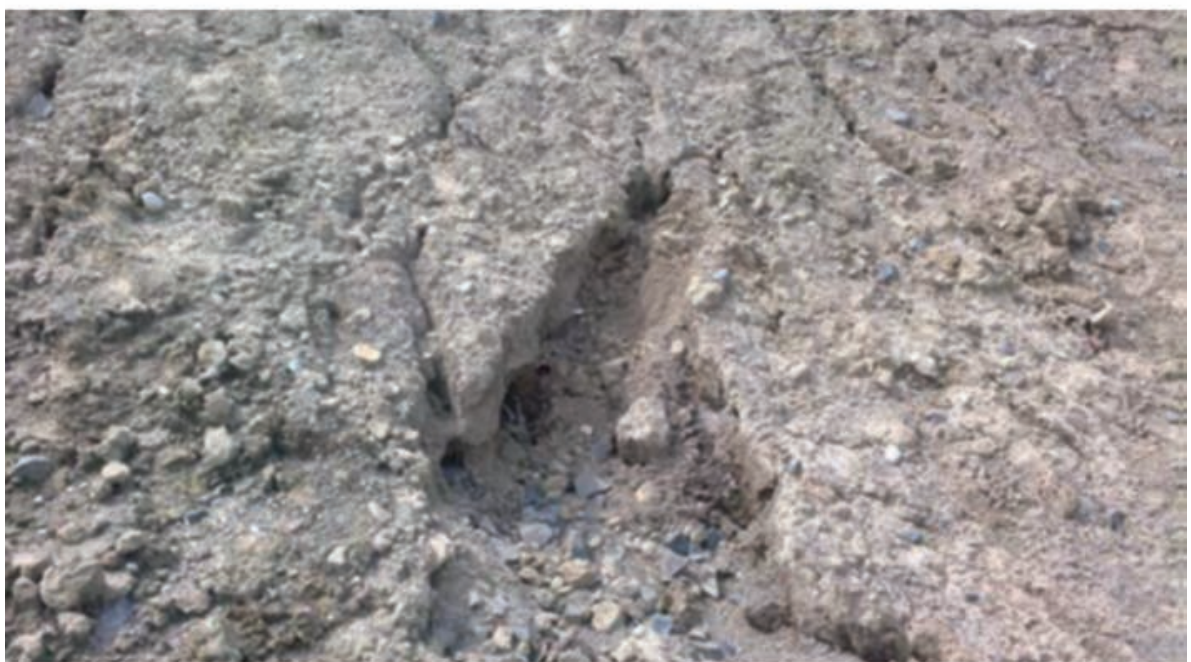

(b)

Figure 1. (a). Railway embankment at the accident site in Malda, India. (b). Gully formation on the embankment slope due to seepage of rain water.

One of the common recommendations made by the investigating team after every accident was to fill up these ponds. These ponds are essentially borrow areas for the embankment materials. These ponds are presently utilized by the local people for the cultivation of fishes. Thus, due to the objections of the local people and issues related to environment protection, filling up these ponds are not possible. On the crest of the embankment, $25 \mathrm{t}$ single axle load from railway locomotives is acting on the both lines (up and down lines). Further, the static load of the locomotives is increased by 30 percent in this study to account for sudden impact. This results in a 66.15 and $2.65 \mathrm{kPa}$ distributed load on top of the actual and the model embankments, respectively. 


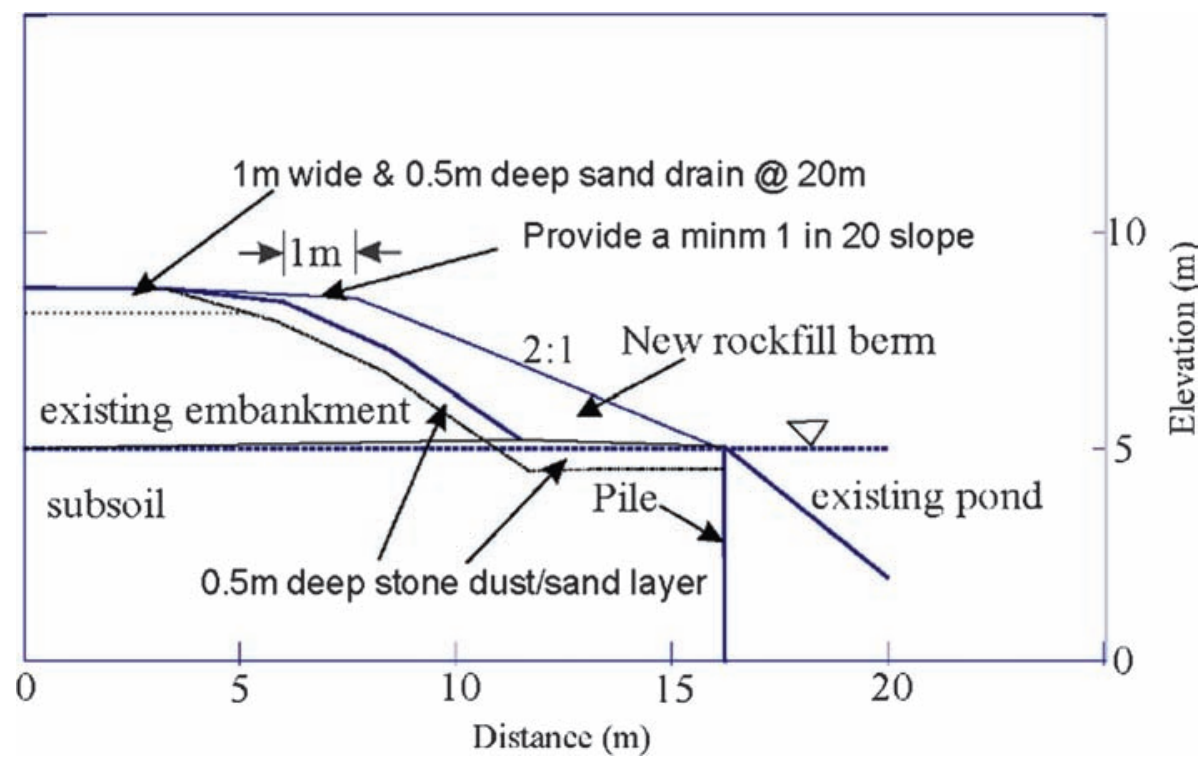

Figure 2. Mitigation measures recommended for the railway embankment at Malda.

\subsection{Soil stratification}

A total of three boreholes are drilled through the existing embankment at the accident sites. All the boreholes are $15 \mathrm{~m}$ deep. Standard Penetration Tests (SPT), undisturbed tube sampling and visual characterization of the soil are performed during the drillings. Loose samples are also collected from $1 \mathrm{~m}$ depth of the existing embankment for the testing and the characterization purposes. The borehole logs indicate that the top $9 \mathrm{~m}$ of the foundation soil is silty clay with medium

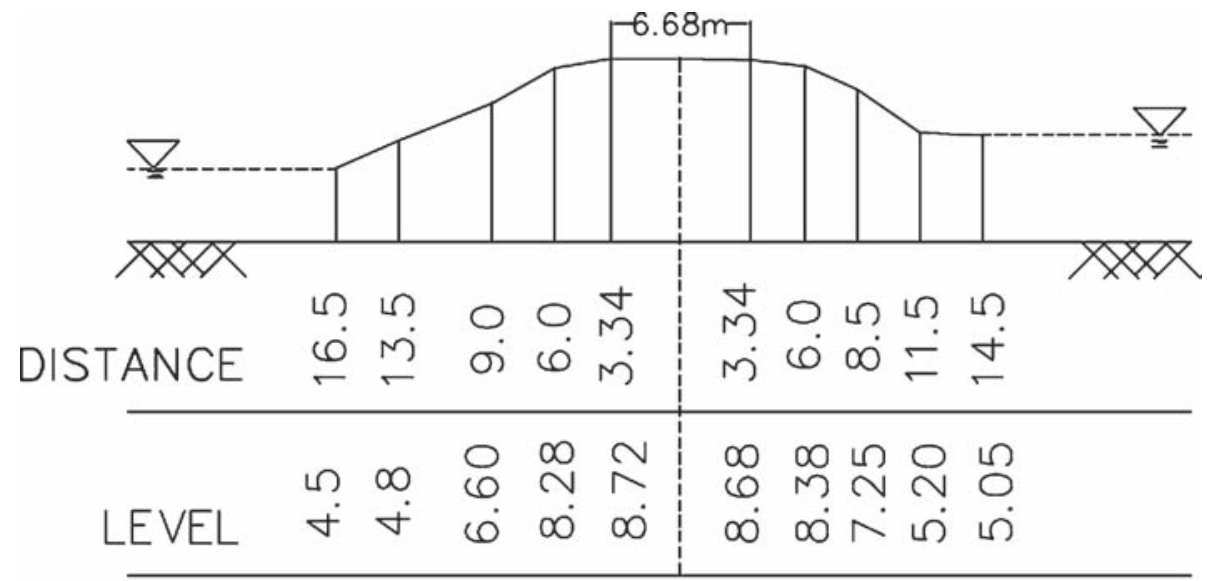

$\operatorname{DISTANCE}(m)$

Figure 3. Geometry of the railway embankment at the accident site in Malda, India. 
consistency. The average SPT blow count for this layer is between 4 and 5 . The undrained shear strength is typically between 25 and $50 \mathrm{kPa}$. Below $9 \mathrm{~m}$, the soil is silty clay with stiff consistency. Traces of fine sand are visible at places. The blow count increases to 10-15 for this layer. Typical undrained shear strength for this layer is found to be between 50 and $100 \mathrm{kPa}$.

\section{Properties of the soil and jute reinforcement}

\subsection{Properties of the Malda soil}

Three undisturbed tube samples from the mid height of the embankment are collected and brought to the laboratory for the determination of the properties. Several standard laboratory tests are performed to determine the properties and classification of the Malda soil. The laboratory specific gravity tests indicate that the soil has a specific gravity of 2.66 . The saturated hydraulic conductivity $k_{s}$ obtained from falling head permeability tests is $8.4 \times 10^{-4} \mathrm{~cm} / \mathrm{s}$. The shear strengths of the soil are obtained from conventional drained direct shear tests. The tests show that the soil has cohesion (c') of $0.2 \mathrm{kPa}$ and an effective internal angle of friction $\left(\phi^{\prime}\right)$ of $29.5^{\circ}$. The grain size distribution of the embankment and top $6 \mathrm{~m}$ of Malda soil is shown in figure 4 . The embankment and the top $6 \mathrm{~m}$ of the soil contain $83 \%$ sand, $16 \%$ silt and $1 \%$ clay. The liquid limit and plasticity index of the soil are 27.5 and 3.6, respectively. As per the Unified Classification System (UCS), the embankment and the top $6 \mathrm{~m}$ Malda soil is classified as SM (Silty Sand). A summary of all the relevant engineering properties of the Malda soil is given in table 1.

\subsection{Properties of jute reinforcement}

Thin jute tassels are considered in the study for the mitigation of the slope. Each jute tassel consists of three jute ropes tied to each other at the top. The jute ropes are of $220 \mathrm{~mm}$ in length and $1 \mathrm{~mm}$ in diameter. A total of 15 such jute tassels are placed along the width of the model

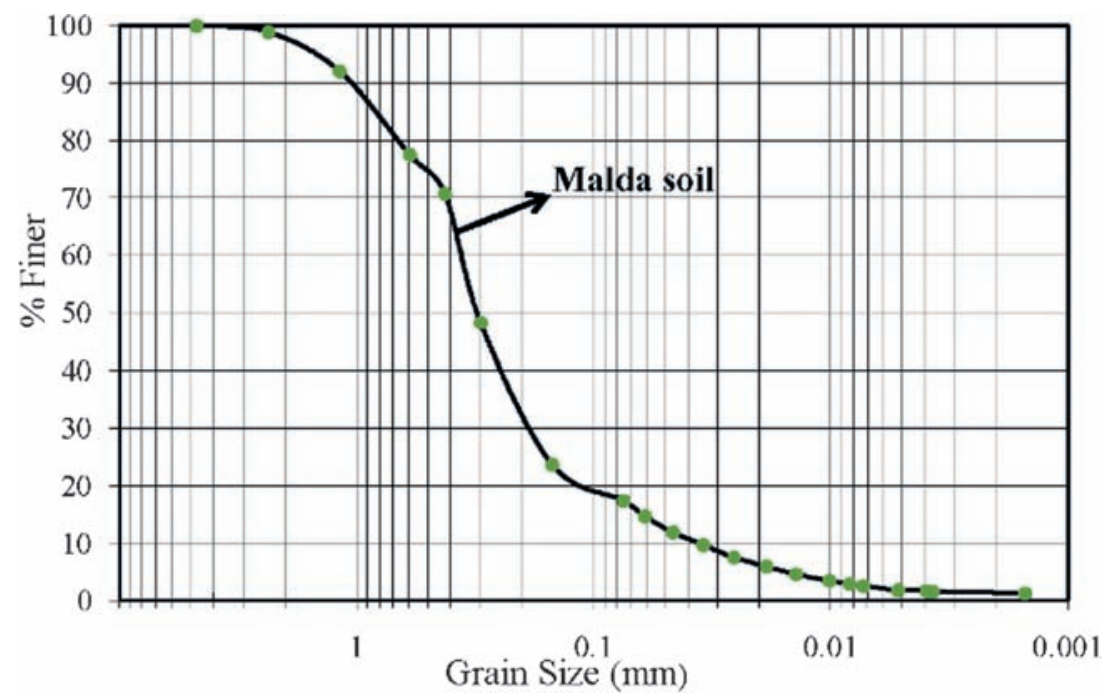

Figure 4. Grain size distribution of Malda soil. 
Table 1. Properties of Malda soil.

\begin{tabular}{lc}
\hline Soil property & Value \\
\hline Dry unit weight $\gamma_{\mathrm{d}}$ & $14.5 \mathrm{kN} / \mathrm{m}^{3}$ \\
Liquid limit $\left(\mathrm{W}_{\mathrm{l}}\right)$ & $27.5 \%$ \\
Plastic limit $\left(\mathrm{W}_{\mathrm{p}}\right)$ & $23.9 \%$ \\
Water content $(\mathrm{w})$ & $29.55 \%$ \\
Specific gravity $(\mathrm{G})$ & 2.66 \\
Friction angle $(\varphi)$ & $29.5^{\circ}$ \\
Cohesion $(\mathrm{c})$ & $0.2 \mathrm{kPa}$ \\
Poisson's ratio & 0.25 \\
Young's modulus $(\mathrm{E})$ & $5.33 \mathrm{MPa}$ \\
Permeability & $8.2 \times 10^{-4} \mathrm{~cm} / \mathrm{sec}$ \\
\hline
\end{tabular}

Table 2. Properties of jute reinforcements.

\begin{tabular}{ll}
\hline Tensile strength & $393 \mathrm{kPa}($ Ahmed \& Vijayarangan 2006) \\
Young's modulus (E) & $20 \mathrm{GPa}($ Ahmed \& Vijayarangan 2006) \\
Poisson's ratio & $0.38($ Ahmed \& Vijayarangan 2006) \\
$\delta_{\text {jute }}$ & $18^{\circ}(0.61 \phi)$ \\
Shear stiffness & $6444 \mathrm{kPa}$ \\
\hline
\end{tabular}

slope. The spacing between two jute tassels is $45 \mathrm{~mm}$. The shear stiffness and coefficient of friction (interface properties) between the jute and the Malda soil is determined from the direct shear tests. A thick plexiglass plate with jute ropes glued on top of it, is placed on the lower half of the 60 by $60 \mathrm{~mm}$ shear box. The upper half of the shear box is then filled with the Malda soil at a dry unit weight of $14.5 \mathrm{kN} / \mathrm{m}^{3}$ (relative density of $65 \%$ ). The entire box is then placed on the direct shear test apparatus and shear test is carried out to find the interface properties between the jute and Malda soil. Some of the other engineering properties of the jute are assumed from the literature (Cheng et al 2003; Hengchaovanich \& Nilaweera 1996; Wang 2000) and are presented in table 2.

\section{Laboratory model tests}

\subsection{Test set-up}

A test set-up has been prepared to conduct the model tests in the laboratory. Figure 5 shows the schematic diagram of the model test set-up. The main components of the test set-up are a test chamber made of plexiglass, a motorized jack and a supporting steel frame. The test chamber, having inside dimensions of $1.0 \times 0.7 \mathrm{~m}$ in plan and a height of $0.13 \mathrm{~m}$ at front side and 0.60 $\mathrm{m}$ at the other three sides, is supported directly on two concrete platforms. The plexiglass walls have a thickness of $16 \mathrm{~mm}$. All the joints are glued as well as reinforced with steel angles and the box may be considered to be rigid. The front side of the test chamber is attached to the bottom platform by two steel hinges so that the test chamber can rotate about these hinges. The backside side of the box is attached to a motorized jack with a steel wire. The jack moves up and down with the help of a motorized pulley and rotates the test chamber with the model slope in it. Before the model tests, all the plexiglass boundaries are lightly greased beforehand to eliminate friction at the boundaries as far as possible. During the test, the entire test chamber with the model embankment within it, is rotated from the initial horizontal position until the slope fails 


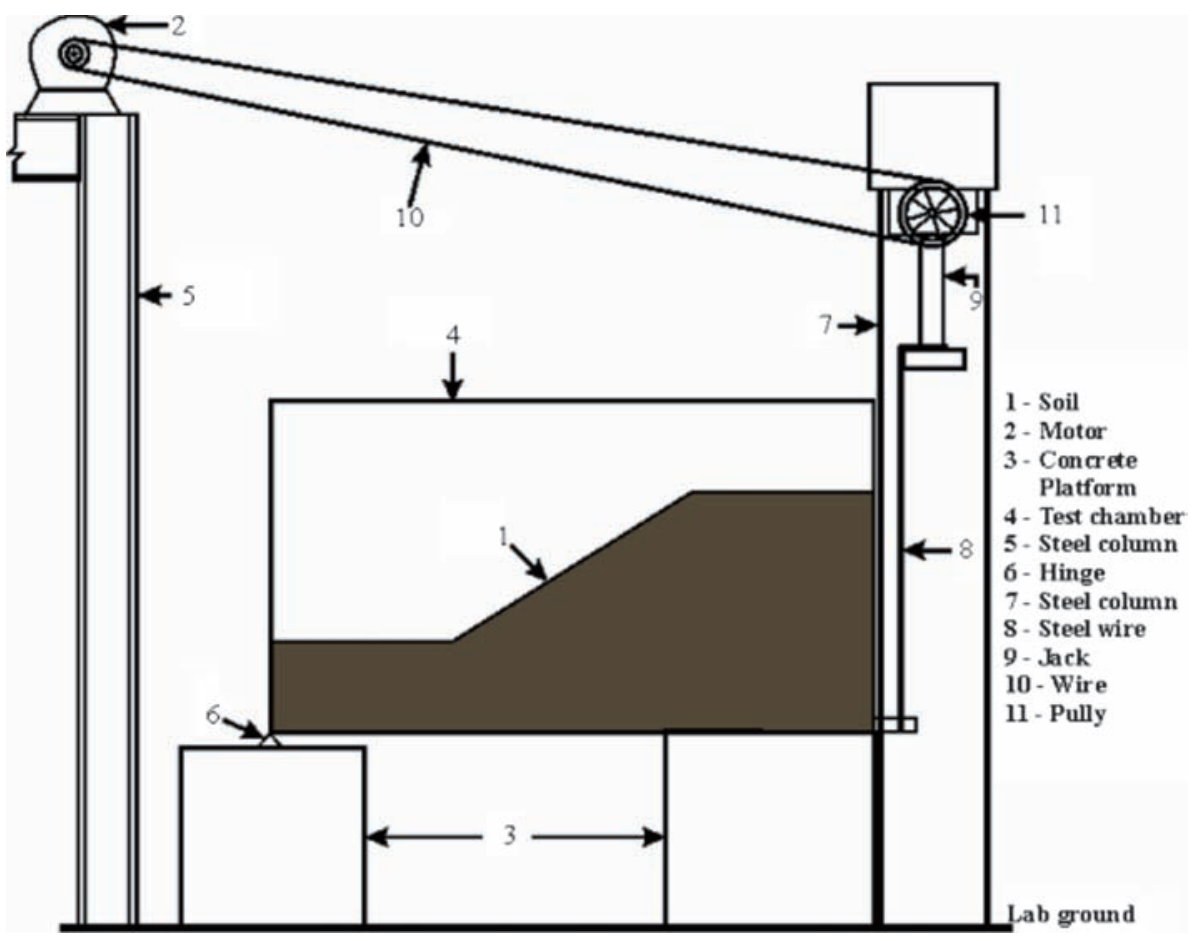

Figure 5. Test set-up for model test.

or up to maximum $16^{\circ}$. Figure 6 a shows the test procedure schematically. This procedure allows one to observe the embankment slope failure by increasing the slope angle effectively without reconstructing the embankment slope and in line with test procedures similar to those reported by Hsu et al (2014) and Schneider et al (2011).

A 1-g scaling law (Ramu et al 2011; Iai 1989) with a scaling factor, $S_{1}=25$ is utilized in obtaining the model geometry of the embankment from the prototype slope geometry of the actual failed railway embankment at Malda and the model size of the jute tassels from the actual size of jute tassels readily available. The scaling of the embankment, the jute tassels and the loads is summarized in table 3. The embankment and the foundation are constructed with the soil collected from the embankment and the top $6 \mathrm{~m}$ of the foundation at the accident site at Malda. The properties of the soil and the jute fibres are not scaled to preserve their frictional and other characteristics. The jute tassels are essentially bundles of jute fibres tied together. In actual case, they come in approximately $100 \mathrm{~mm}$ in diameter and 5 to $6 \mathrm{~m}$ in length (Wang 2000; Cheng et al 2003). The jute tassels used in this study are only $1 \mathrm{~mm}$ in diameter and $220 \mathrm{~mm}$ in length. In order to obtain the deformations and settlement of the actual (prototype) slope, the deformations and settlement obtained from the model study need to be scaled up by multiplying them by the scaled factor $\left(S_{1}=25\right)$. Due to symmetry, only one side of the embankment is modelled in the laboratory. The slope is prepared in 5 to 6 lifts maintaining a uniform dry density of $14.5 \mathrm{kN} / \mathrm{m}^{3}$. The model embankment consists of a $2(\mathrm{H}): 1(\mathrm{~V})$ slope with height of 0.225 $\mathrm{m}$ and crest width of $0.28 \mathrm{~m}$. At the bottom of the embankment, a $0.132 \mathrm{~m}$ thick foundation is provided. On the downstream side, the foundation extends up to $0.27 \mathrm{~m}$ (up to the end of the test chamber) from the toe of the embankment. The length of the model embankment, model 
Slope rotated by an angle $\alpha$

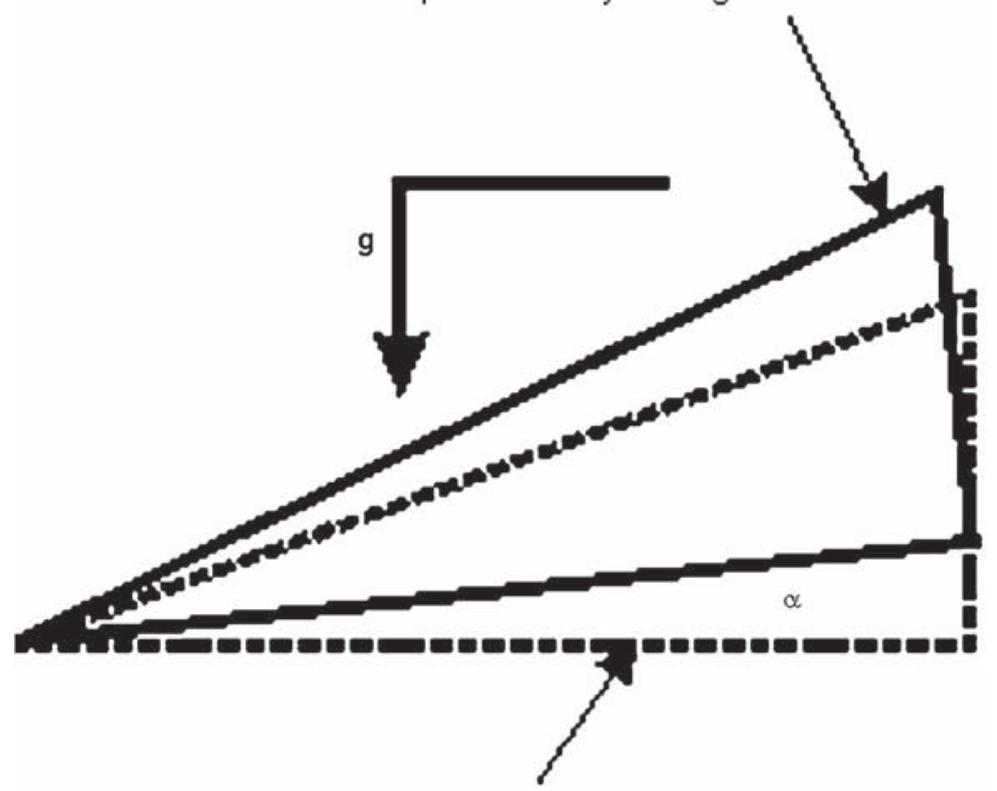

Initial position of the slope

(a)

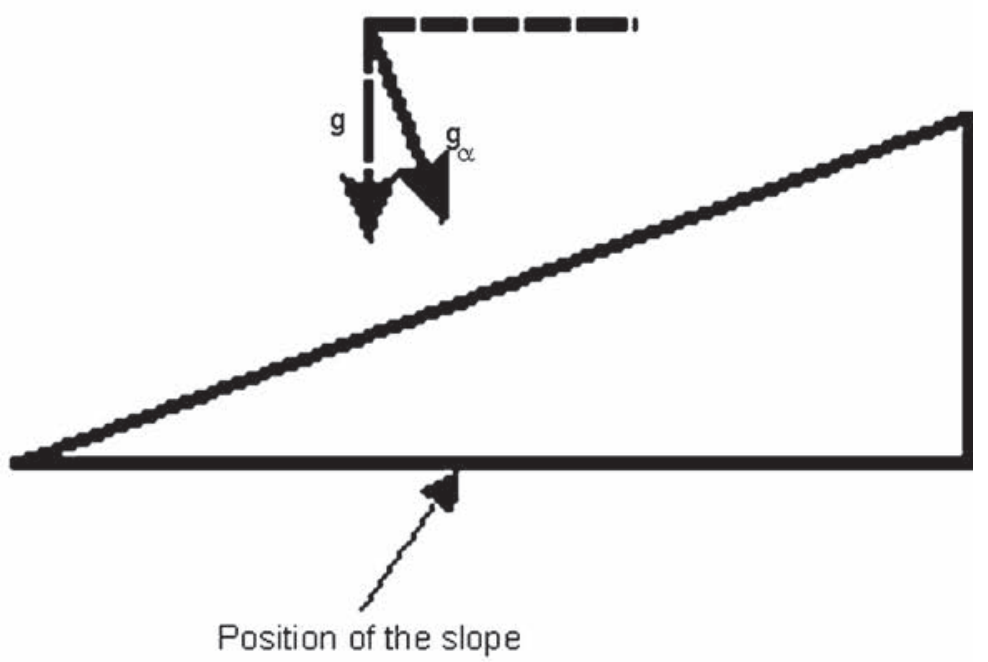

(b)

Figure 6. Schematic diagram of (a) Test procedure, (b) Procedure for numerical analyses.

foundation and the width of the test chamber are $0.7 \mathrm{~m}$. The railway embankments in Malda are designed for $25 \mathrm{t}$ single axle load from the railway locomotives which are acting on both lines (up and down lines) located on top of it. This results in a $66.15 \mathrm{kPa}$ distributed load on the crest of the embankment. By applying the 1-g scaling law, the load is reduced to $2.65 \mathrm{kPa}$. To apply 
Table 3. Scaling of embankment, jute tassels and surcharge load.

\begin{tabular}{lcccc}
\hline Parameters & Model & Model value & Prototype & Prototype value \\
\hline Height of the slope & $\mathrm{L}_{\mathrm{m}}$ & $0.225 \mathrm{~m}$ & $\mathrm{~S}_{1} \times \mathrm{L}_{\mathrm{m}}$ & $5.63 \mathrm{~m}$ \\
Crest width & $\mathrm{L}_{\mathrm{m}}$ & $0.28 \mathrm{~m}$ & $\mathrm{~S}_{1} \times \mathrm{L}_{\mathrm{m}}$ & $7 \mathrm{~m}$ \\
Slope length & $\mathrm{L}_{\mathrm{m}}$ & $0.45 \mathrm{~m}$ & $\mathrm{~S}_{1} \times \mathrm{L}_{\mathrm{m}}$ & $11.25 \mathrm{~m}$ \\
Jute tassel length (L) & $\mathrm{L}_{\mathrm{m}}$ & $220 \mathrm{~mm}$ & $\mathrm{~S}_{1} \times \mathrm{L}_{\mathrm{m}}$ & 0.31 to $9.56 \mathrm{~m}$ (Wang 2000) \\
Jute tassel diameter(D) & $\mathrm{D}_{\mathrm{m}}$ & $1 \mathrm{~mm}$ & $\mathrm{~S}_{1} \times \mathrm{D}_{\mathrm{m}}$ & $0.66 \pm 0.32 \mathrm{~mm}$ (Cheng et al 2003) \\
Young's modulus (E) of jute & $\mathrm{E}_{\mathrm{m}}$ & $20 \mathrm{GPa}$ & $\mathrm{S}_{1} \times \mathrm{E}_{\mathrm{m}}$ & $500 \mathrm{GPa}$ \\
$\delta_{\text {jute-soil }}$ & - & $18^{\circ}(0.61 \phi)$ & 1 & $18^{\circ}(0.61 \phi)$ \\
Shear stiffness (k) of jute & $\mathrm{k}_{\mathrm{m}}$ & $6444 \mathrm{kPa}$ & $\mathrm{S}_{1}^{2} \times \mathrm{k}_{\mathrm{m}}$ & $4027.5 \mathrm{GPa}$ \\
Tensile strength (S) of jute & $\mathrm{S}_{\mathrm{m}}$ & $393 \mathrm{kPa}$ & $\mathrm{S}_{1} \times \mathrm{S}_{\mathrm{m}}$ & $85.10 \pm 31.2 \mathrm{MPa}(\mathrm{Cheng}$ et al 2003) \\
Surcharge load (q) & $\mathrm{q}_{\mathrm{m}}$ & $2.65 \mathrm{kPa}$ & $\mathrm{S}_{1} \times \mathrm{q}_{\mathrm{m}}$ & $66.15 \mathrm{kPa}$ \\
\hline
\end{tabular}

$\mathrm{S}_{1}=$ a scaling factor $=25$ in the present case

this uniformly distributed load on the crest of the model embankment, a rigid and light weight wooden plank, of the same width as that of the crest, is placed on top of the crest and a $38.5 \mathrm{~kg}$ load is placed securely on top of the wooden plank. To prevent the wooden platform from slipping, it is nailed to the top of the embankment by several $25.4 \mathrm{~mm}$ iron nails.

\subsection{Experimental procedure}

The model slope is constructed within the plexiglass test chamber in five layers to maintain a uniform dry unit weight of $14.5 \mathrm{kN} / \mathrm{m}^{3}$ (relative density of $65 \%$ ). The finished surface of the slope is prepared by hand modelling tools. In the case of model slope reinforced with the rows of jute tassels, the reinforcements are placed after the construction of the slope. Vertical holes of $25 \mathrm{~mm}$ in diameter and $220 \mathrm{~mm}$ in length are drilled through the slope with a hand auger. The soil around the holes is moistened to facilitate the process. The jute tassels are then inserted into these holes and the holes are filled back with the soil if required. It is ensured that all the jute tassels penetrate well into the stable foundation below. The first row of jute tassels is placed on the slope at $170 \mathrm{~mm}$ from the toe. The second row of jute tassels is placed on the slope at 270 $\mathrm{mm}$ from the toe.

After the construction, the slope is fully saturated by adding water. The front and back sides of the plexiglass test chamber are double walled with a gap in between. The inner walls are perforated to allow water in and out of the test chamber. The gap between the backside walls is continuously filled with water and it is allowed to percolate into the constructed soil slope within the test chamber. The water coming out of the slope is drained away through the front. The water is supplied to the slope continuously throughout the whole time of the tests. During the saturation process and during the tests, the pore water pressure/suction pressures within the constructed embankment are measured by T5-7 tensiometers to ensure full saturation and no suction pressures.

The deformations of the slope in saturated condition with and without jute reinforcements are measured at every $50 \mathrm{~mm}$ interval along the length of the slope. Lines are drawn on both sides (left and right) of the test chamber to keep track of the original slope. The deformations are measured manually on both sides of the slope. Photographs are also taken from the two sides of the slope from two fixed positions. The deformations along the centreline of the slope are measured by a Laser Displacement Transducer (LDT). The test chamber along with the 
embankment slope in it is rotated. Measurements are taken when the test container is horizontal, and for every $5^{\circ}$ increase in effective slope angle.

\section{Numerical analyses}

The numerical analyses of the embankment with and without jute reinforcements have been done by a computer program called FLAC (Fast Lagrangian Analysis of Continua) developed by the Itasca Consulting Group (2005). A 2-D plane strain, effective stress analysis is performed for the scaled embankment slope tested in the laboratory. The container box is not modelled. The boundary conditions assumed in the numerical model consist of constraining the x-displacement normal to the two sides of the slope i.e., roller supports are provided on these two sides of the slope model. At the bottom of the slope both $\mathrm{x}$ and $\mathrm{y}$ displacement are fixed i.e., fixed support is provided at the bottom.

The embankment and the foundation soil are modelled as a Mohr-Coulomb materials. All the soil parameters (table 1) are obtained from the laboratory tests of the Malda soil collected from the field and specified for the numerical model. The jute reinforcements are modelled as cable elements. The cable elements are one-dimensional axial elements. The cables can yield in tension or compression, but they cannot sustain a bending moment. The FLAC program utilized in this study is two-dimensional; the three-dimensional effect of regularly spaced elements (cables) is accommodated by scaling their material properties in the out-of-plane direction. Some of the properties of the jute reinforcements are obtained from the literature and some from the laboratory tests and are given in table 2 . Figure 7 shows the dimensions and the numerical discretization of the embankment. The cable elements representing the jute reinforcements are shown in the inset of figure 7 .
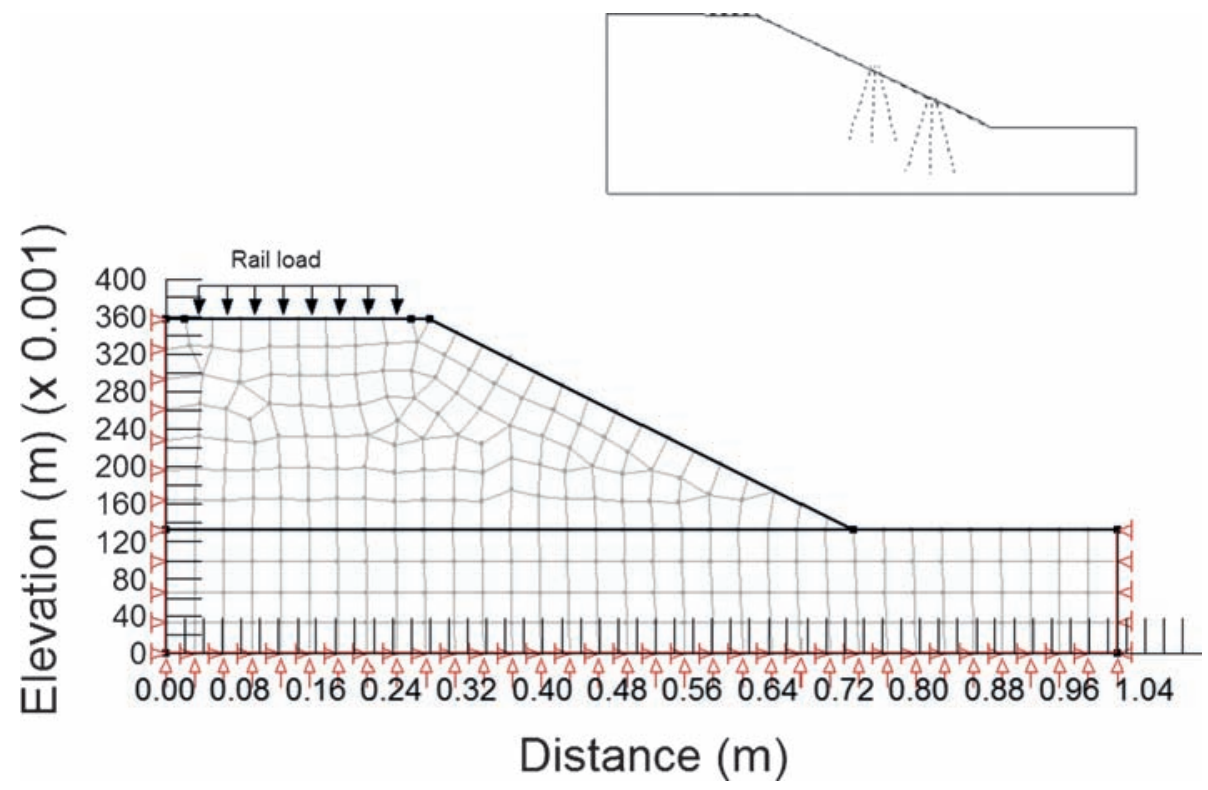

Figure 7. Geometry and numerical discretization of the embankment (Position of the cable elements representing jute reinforcements are shown in the inset). 
The numerical analyses of the scaled model of the saturated embankment are performed with and without jute reinforcements for four positions of the embankment slope-horizontal condition, slope rotated by $5^{\circ}$, slope rotated by $10^{\circ}$ and slope rotated by $16^{\circ}$. The $5^{\circ}, 10^{\circ}$ and $16^{\circ}$ rotation of the entire slope is simulated in the numerical model by rotating the axis (direction) of the gravity by $5^{\circ}, 10^{\circ}$ and $16^{\circ}$, respectively. Figure $6 \mathrm{~b}$ shows the above numerical procedure schematically. This type of procedure is adopted by Hill et al (2011) for the analysis of large flow/rotational deformations. In all the cases, a scaled surcharge pressure of $2.65 \mathrm{kPa}$ is applied on the crest of the embankment as also done in the laboratory experiments to simulate the load coming from locomotives.

\section{Results and discussions}

\subsection{Embankment without any reinforcement}

The results of the laboratory model tests and the numerical analyses of the model embankment with and without jute reinforcements are presented in terms of slope (surface) displacements and theoretical factor of safety. Table 4 compares the maximum displacements obtained from the laboratory model tests and the numerical analyses for the saturated embankment slope without any reinforcement. The maximum displacements obtained from the model tests and the numerical analyses are comparable for the first three effective slopes, that is, when the effective slopes are 2:1, 1.6:1 and 1.4:1. The deformations of the whole slope for the case of effective slopes of 2:1 and 1.4:1 as obtained from the model tests and the numerical analyses are shown in figures 8 and 9, respectively. For the case of 2:1 slope, the maximum deformation is observed at the outer edge of the crest. Though the maximum deformations are more or less same but the deformation pattern for the case of 1.4:1 slope is found to be quite different between the numerical analyses and the model tests. The model tests indicate the sliding of the slope surface while the numerical analyses show a settlement of the crest and a bulging at the toe. For the case of 1.4:1 slope, the experimental study shows maximum deformation at the outer edge of the crest while the numerical analyses show it at the toe of the slope. The discrepancy between the test results and the numerical results observed in figure 9 is arising due to the limitations of the numerical analyses in modelling a large flow problem.

\subsection{Embankment with a single row of jute reinforcements}

In these cases, the jute tassels are placed along a single row across the model embankment slope at a horizontal distance of $170 \mathrm{~mm}$ from the toe. Table 5 compares the maximum displacements of the saturated embankment slope with the single row of jute reinforcement obtained from the laboratory model tests and the numerical analyses. The maximum displacements obtained from

Table 4. Comparison of the results of the laboratory model tests and numerical analyses for the saturated embankment without any reinforcements.

\begin{tabular}{lccc}
\hline $\begin{array}{l}\text { Position of the } \\
\text { test chamber }\end{array}$ & $\begin{array}{c}\text { Effective embankment } \\
\text { slope }\end{array}$ & From model test & From numerical analyses \\
\hline Horizontal & $2(\mathrm{H}): 1(\mathrm{~V})$ & 15.68 & 15.00 \\
Rotated $5^{\circ}$ & $1.6(\mathrm{H}): 1(\mathrm{~V})$ & 39.9 & 40.52 \\
Rotated $10^{\circ}$ & $1.4(\mathrm{H}): 1(\mathrm{~V})$ & 63.76 & 64.68 \\
Rotated $16^{\circ}$ & $1(\mathrm{H}): 1(\mathrm{~V})$ & 92.68 & 109.70 \\
\hline
\end{tabular}




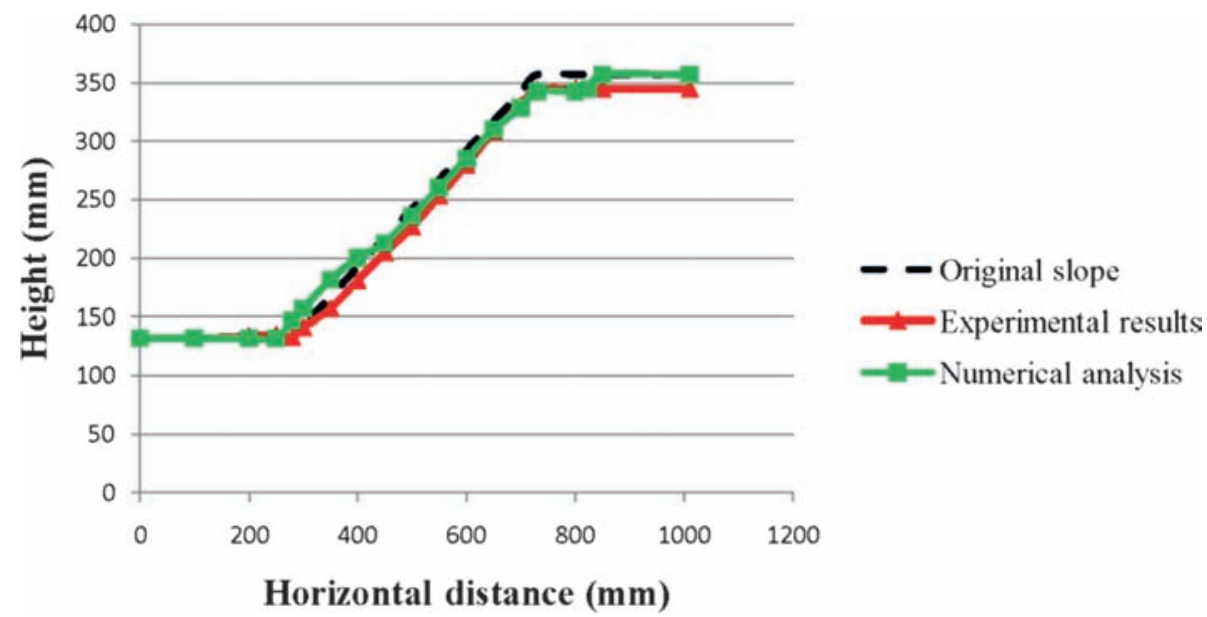

Figure 8. Comparison of test and numerical analysis of 2:1 Slope without reinforcement.

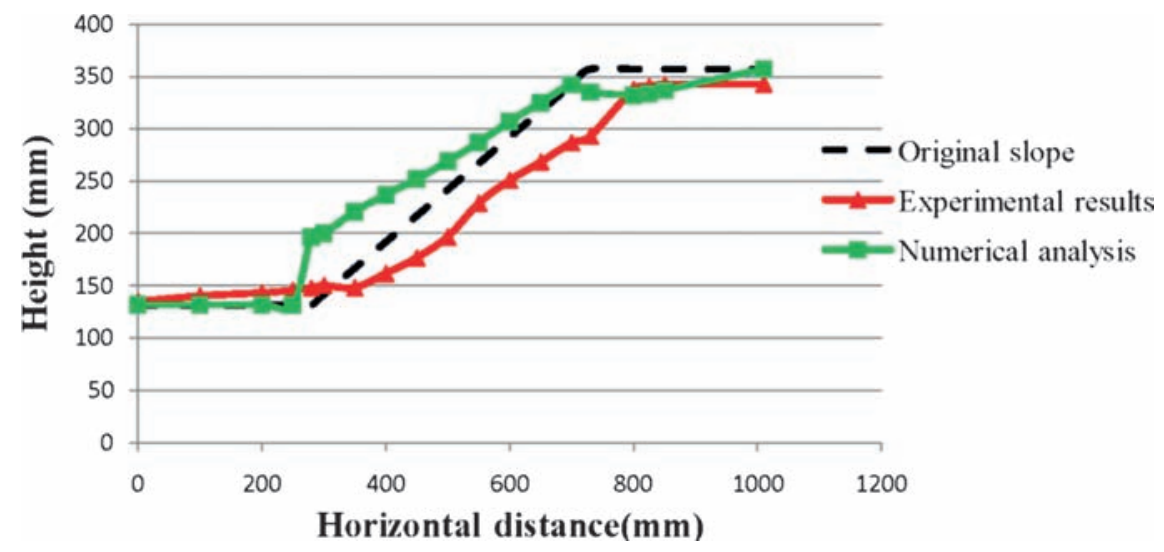

Figure 9. Comparison of test and numerical analysis of 1.4:1 slope without reinforcement.

Table 5. Comparison of the results of the laboratory model tests and numerical analyses for the saturated embankment with a single row of jute reinforcements.

\begin{tabular}{lccc}
\hline $\begin{array}{l}\text { Position of the } \\
\text { test chamber }\end{array}$ & $\begin{array}{c}\text { Effective embankment } \\
\text { slope }\end{array}$ & From model test & From numerical analyses \\
\hline Horizontal & $2(\mathrm{H}): 1(\mathrm{~V})$ & 10.96 & 7.13 \\
Rotated $5^{\circ}$ & $1.6(\mathrm{H}): 1(\mathrm{~V})$ & 32.4 & 32.92 \\
Rotated $10^{\circ}$ & $1.4(\mathrm{H}): 1(\mathrm{~V})$ & 50.25 & 48.19 \\
Rotated $16^{\circ}$ & $1(\mathrm{H}): 1(\mathrm{~V})$ & 64.5 & 62.22 \\
\hline
\end{tabular}

the model tests and the numerical analyses are found to be comparable for all the cases, that is, for the effective slopes of 2:1, 1.6:1 and 1.4:1. The results of model tests as well as numerical analyses predict quite significant reduction in maximum deformations when compared to the cases with the unreinforced slope. For the 2:1 slope, the maximum deformation reduces to $10.96 \mathrm{~mm}$ 
from 15.68 by placing a single row of jute tassels. The maximum deformation reduces to 50.25 from $63.76 \mathrm{~mm}$ by placing a single row of jute tassels in 1.4:1 slope. These reductions in deformations are quite significant. The deformations of the whole slope obtained from the model tests and the numerical analyses are compared in figures 10 and 11 for the effective slopes of 2:1 and 1.4:1, respectively. As may be seen from figure 11, the numerical results show bulging of the toe contrary to the observations in the model test. This again may be due to the limitation of the numerical model in representing large debris flow problems. The model test indicates that there have been very little deformations of the slope between the place where a row of the jute tassel has been planted and the toe of the model embankment. The model tests show the effect of the placement of the jute tassels but the numerical analyses are not showing its effect that prominently. However, the numerical analyses also show significant reduction in deformations with the plantation of a single row of jute tassels. The maximum deformation reduces to 48.19 from $64.68 \mathrm{~mm}$ in the numerical analyses for the case of 1.4:1 effective slope.

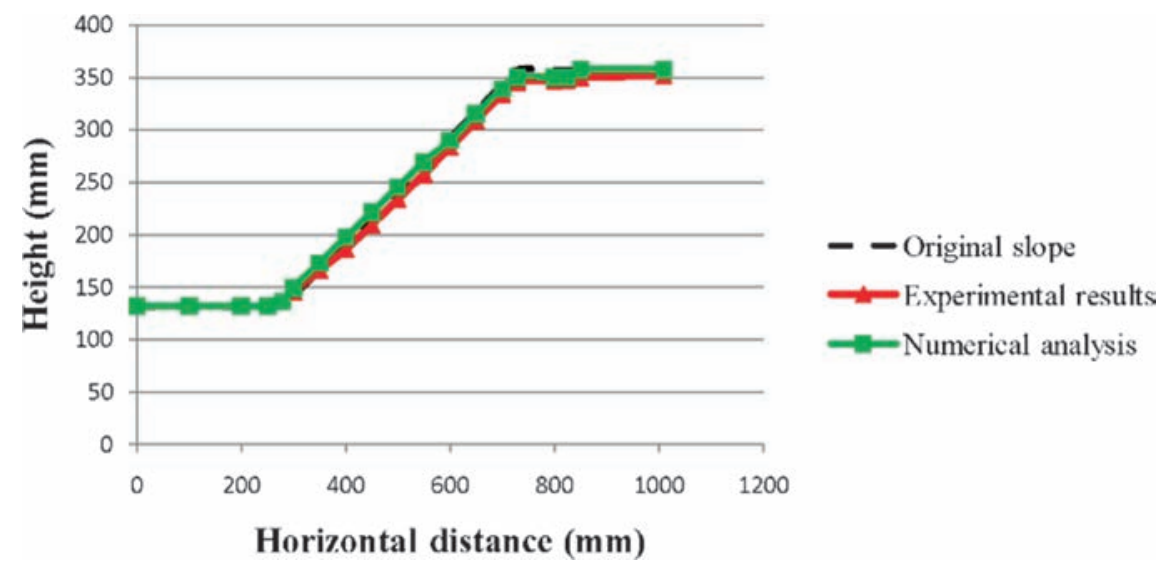

Figure 10. Comparison of test and numerical analysis of 2:1 slope with a single row of jute tassels.

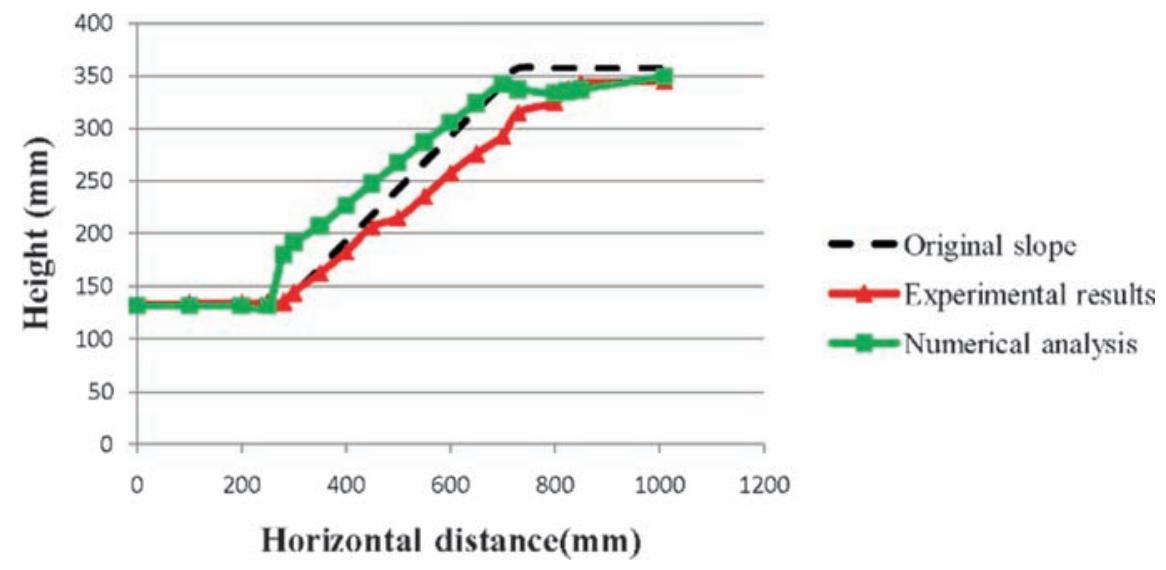

Figure 11. Comparison of test and numerical analysis of 1.4:1 slope with a single row of jute tassels. 


\subsection{Embankment with two rows of jute reinforcements}

In these cases, the jute tassels are placed along two rows across the model embankment slope at horizontal distances of 170 and $270 \mathrm{~mm}$ from the toe. Table 6 compares the maximum displacements of the saturated embankment slope for this case obtained from the laboratory model tests and the numerical analyses. The maximum displacements obtained from the model tests and the

Table 6. Comparison of the results of the laboratory model tests and numerical analyses for the saturated embankment with two rows of jute reinforcements.

\begin{tabular}{lccc}
\hline $\begin{array}{l}\text { Position of the } \\
\text { test chamber }\end{array}$ & $\begin{array}{c}\text { Effective embankment } \\
\text { slope }\end{array}$ & From model test & From numerical analyses \\
\hline Horizontal & $2(\mathrm{H}): 1(\mathrm{~V})$ & 6.5 & 3.74 \\
Rotated $5^{\circ}$ & $1.6(\mathrm{H}): 1(\mathrm{~V})$ & 12.57 & 12.58 \\
Rotated $10^{\circ}$ & $1.4(\mathrm{H}): 1(\mathrm{~V})$ & 20.61 & 18.9 \\
Rotated $16^{\circ}$ & $1(\mathrm{H}): 1(\mathrm{~V})$ & 34.78 & 34.68 \\
\hline
\end{tabular}

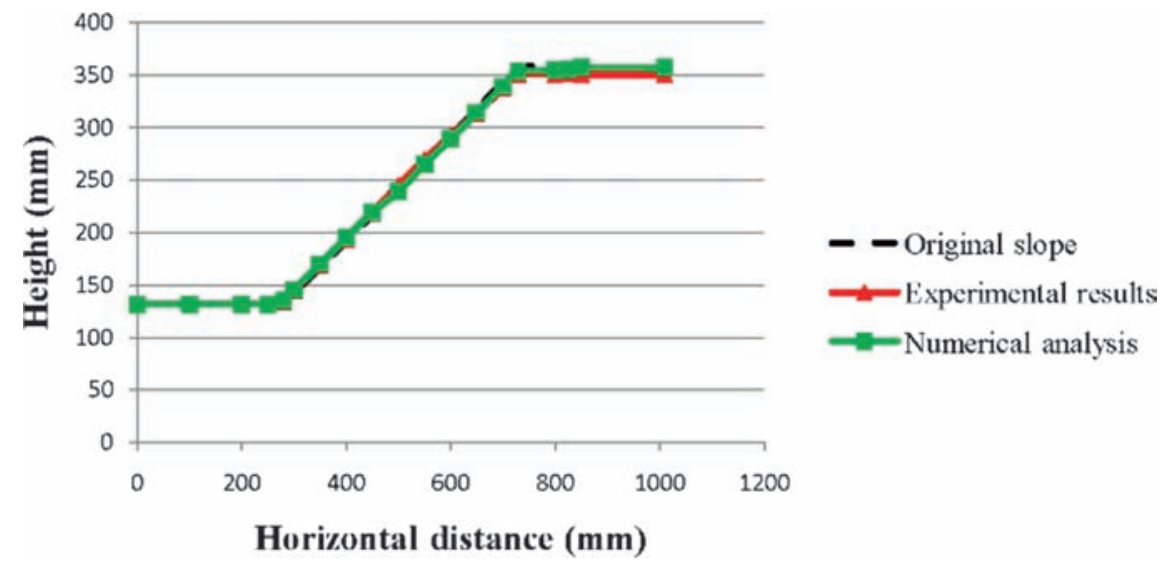

Figure 12. Comparison of test and numerical analysis of 2:1 slope with two rows of jute tassels.

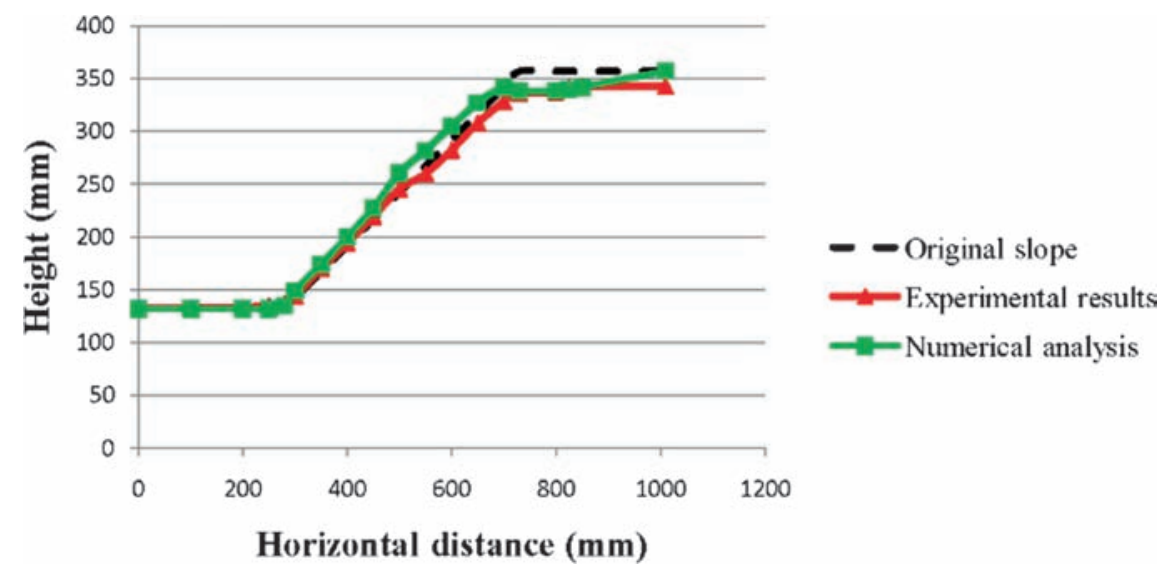

Figure 13. Comparison of test and numerical analysis of 1.4:1 slope with two rows of jute tassels. 
numerical analyses are found to be comparable for all the cases. The results of model tests as well as numerical analyses predict further significant reduction in maximum deformations when compared to the cases with the unreinforced slope and slope with one row of jute tassels. For the $2: 1$ slope, the maximum deformation reduces to 6.5 from $15.68 \mathrm{~mm}$ by placing two rows of jute tassels on the slope. The maximum deformation reduces to 20.61 from $63.76 \mathrm{~mm}$ by placing two rows of jute tassels in 1.4:1 slope. These reductions in deformations are quite significant. The deformations of the whole slope obtained from the model tests and the numerical analyses for this case are compared in figures 12 and 13 for the effective slopes of 2:1 and 1.4:1, respectively. As may be seen from these figures, the bulging of the toe noticed in earlier numerical analyses is not present in this case. The test results show almost no deformation below the second row of the jute reinforcements. The experimental and numerical results are quite comparable. The maximum crest settlement in this case is found to be $6.5 \mathrm{~mm}$ by both numerical

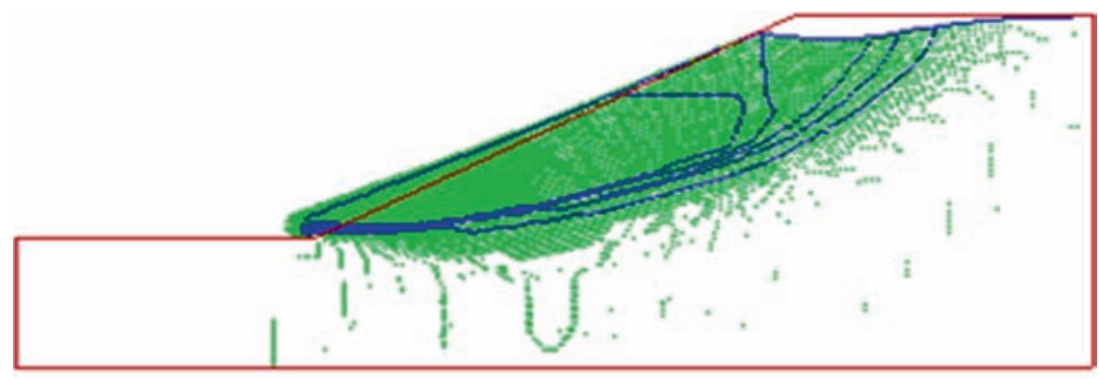

(a)

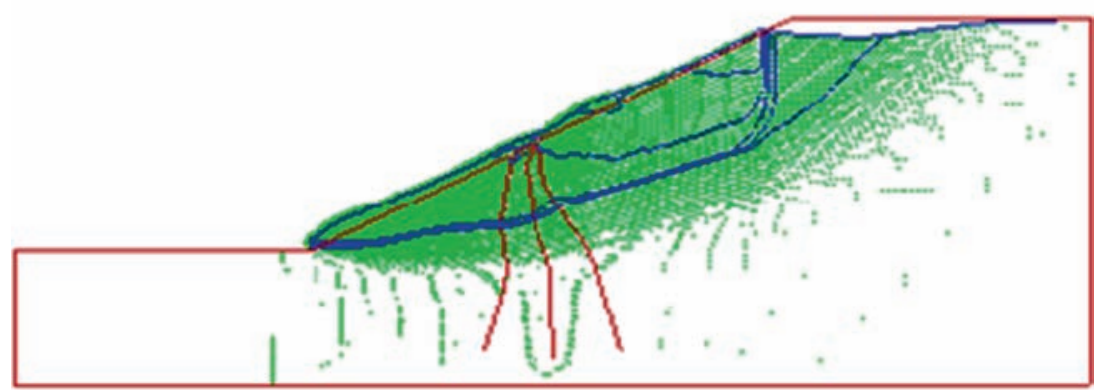

(b)

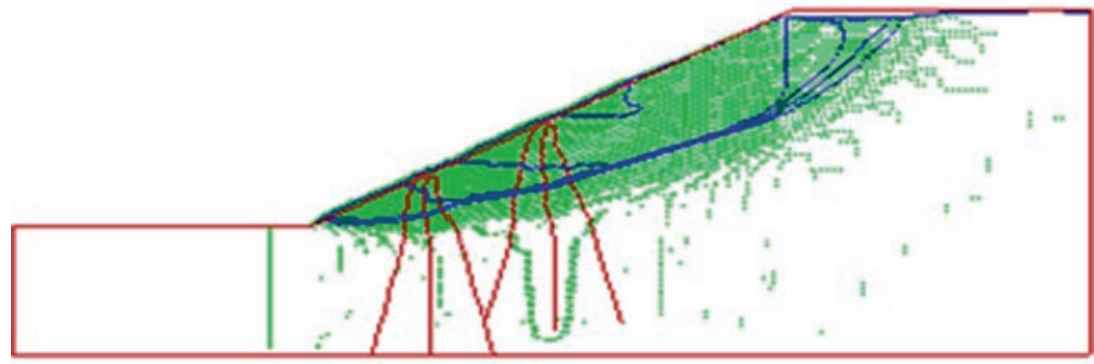

(c)

Figure 14. Comparison of the deformation of the 1.4:1 slope (a) without reinforcement, (b) with a single row of jute reinforcement, and (c) with two rows of jute reinforcements. 
Table 7. Factors of Safety of the embankment slope under different conditions from the numerical analyses.

\begin{tabular}{|c|c|c|c|c|c|}
\hline \multirow[b]{2}{*}{$\begin{array}{l}\text { Position of the } \\
\text { test chamber }\end{array}$} & \multirow{2}{*}{$\begin{array}{c}\text { Effective } \\
\text { embankment } \\
\text { slope }\end{array}$} & \multirow{2}{*}{$\begin{array}{l}\text { Dry condition } \\
\text { Without } \\
\text { reinforcement }\end{array}$} & \multicolumn{3}{|c|}{ Fully saturated condition } \\
\hline & & & $\begin{array}{c}\text { Without } \\
\text { reinforcement }\end{array}$ & $\begin{array}{l}\text { With single row } \\
\text { of jute reinforcement }\end{array}$ & $\begin{array}{l}\text { With double rows } \\
\text { of jute reinforcement }\end{array}$ \\
\hline Horizontal & $2(\mathrm{H}): 1(\mathrm{~V})$ & 2.51 & 1.22 & 1.87 & 1.96 \\
\hline Rotated $5^{\circ}$ & $1.6(\mathrm{H}): 1(\mathrm{~V})$ & 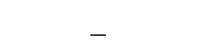 & 1.04 & 1.46 & 1.6 \\
\hline Rotated $10^{\circ}$ & $1.4(\mathrm{H}): 1(\mathrm{~V})$ & - & 0.7 & 1.03 & 1.16 \\
\hline Rotated $16^{\circ}$ & $1(\mathrm{H}): 1(\mathrm{~V})$ & - & 0.13 & 0.84 & 1.0 \\
\hline
\end{tabular}

analyses and laboratory tests. This value is significantly less than $11 \mathrm{~mm}$ obtained for the case with one row of jute reinforcements and $13 \mathrm{~mm}$ of crest settlement observed in the case of unreinforced model embankment. Figure 14 compares the numerical results (slope deformations) for the cases of 1.4:1 slope without any reinforcement, with a single row of jute reinforcement and with two rows of jute reinforcements. The results prove very convincingly that two rows of jute reinforcements on the slope can significantly reduce the slope settlement and deformations.

\subsection{Factor of safety of the embankment}

The theoretical factor of safety for all the cases considered here are computed by FLAC and presented in table 7 . The factor of safety of the model embankment with 2:1 slope decreases from 2.51 to 1.22 as the embankment becomes fully saturated from the initial dry condition. The factor of safety increases from 1.22 to 1.96 when two rows of jute tassels are planted on the saturated slope. For the 1.4:1 saturated slope, the factor of safety increases from 0.7 to 1.16 by planting two rows of jute tassels. This is a significant increase in the factor of safety. Note that the factor of safety being ratio of two stress quantities is not influenced by the scaling or the scale factor. The results show that reinforcing the of an embankment by jute straws or tassels may significantly improve the slope stability and may be considered as an environment-friendly and low-cost slope stabilization measure.

\section{Conclusions}

From all the model tests performed in the laboratory and the numerical analyses, it is clear that the inclusion of the jute tassels on the slope, significantly reduces the deformation of a slope in fully saturated condition. The jute tassels act as tensile reinforcements and increase resistance along probable slip surfaces. As a consequence, the stability of the soil slope is improved. Both the model tests and the numerical analyses indicate that planting double rows of jute tassels on the slope significantly improve the stability of the slope as compared to the slope with a single row of jute tassels and slope without any reinforcements. The deformations of the slope computed by the numerical analyses are found to be reasonably close to those observed in the model tests performed in the laboratory. Both show that the crest settlement may be reduced by half by planting two rows of jute tassels on the embankment slope. The results confirm that plantation of jute tassels may significantly improve the slope stability and may be considered as an environment-friendly and low cost-slope stabilization measure. 


\section{References}

Ahmed K Sabeel and Vijayarangan S 2006 Elastic property evaluation of Jute-glass fibre hybrid composite using experimental and CLT approach. Indian J. Eng. Mater. Sci. 13: 435-442

Au S W C 1998 Rain-induced slope instability in Hong Kong. Eng. Geol. 51(1): 1-36

Ausilio E, Conte E and Dente G 2001 Stability analysis of slopes with piles. Comput. Geotech. 28: 591-611

Cheng H, Yang X and Liu A 2003 An experimental study on mechanical performance and mechanism of soil-reinforcement by herb root system. In Proceedings of the Third International Conference on Vetiver and Exhibition, Guangzhou, China

Fourie A B 1996 Predicting rainfall-induced slope instability. Proceedings of the Institution of Civil Engineers-Geotechnical Engineering 119(4): 211-218

Fowze J S M, Bergado D T, Soralump S and Voottipreux P 2012 Rain-triggered landslide hazards and mitigation measures in Thailand: From research to practice. J. Geotextiles and Geomembranes 30: 50-64

Grimshaw R G 1994 Vetiver grass-its use for slope and structure stabilizatioon under tropical and semitropical conditions. In: Vegetation and Slopes, Institution of Civil Engineers, London, pp. 26-35

Hengchaovanich D and Nilaweera N 1996 An assessment of strength properties of vetiver grass roots in relation to slope stabilization. Proceedings of the First International Conference on Vetiver, Office of the Royal Development Projects Board, Bangkok, pp. 153-158

Hill K, Yohannes B, Dietrich W and Hsu L 2011 Discrete Element Modeling and Large Scale Experimental Studies of Bouldery Debris Flows, In R Genevois; D L Hamilton and A Prestininzi (ed.) Proceedings of the 5th International Conference on Debris Flow Hazards Mitigation, Mechanics, Prediction and Assessment, Padua, Italy, June 14-17, 2011, Italian Journal of Engineering Geology and Environment

Hsu L, Dietrich W E and Sklar L S 2014 Mean and fluctuating basal forces generated by granular flows: laboratory observations in a large vertically rotating drum. J. Geophys. Res.- Earth Surface, DOI: 10.1002/2013JF003078

Iai S 1989 Similitude for shaking table tests on soil-structure-fluid model in $1 \mathrm{~g}$ gravitational field. Soils and Foundations 29(1): 105-118

Itasca Consulting Group Inc 2005 FLAC (Fast Lagrangian Analysis of Continua), Version 5.0, ICG, Minneapolis, Minnesota, USA

Ramu M, Prabhu Raja V and Thyla P R 2011 Development of structural similitude and scaling laws for elastic models. KSCE J. Civil Eng. 17(1): 139-144

RDSO 2011 Rehabilitation of Unstable Formation between Gour Malda and Jamirghata Stations, Malda Division, Eastern Railway. Consultancy Report No. RDSO/2011/GE:CR-0157, Geotechnical Engineering Directorate, RDSO, Lucknow, India

RDSO 1998 Rehabilitation of Weak Formation between Gour Malda and Malda Town on Malda Division Eastern Railway. Consultancy Report No: GE-20, Geotechnical Engineering Directorate, RDSO,Lucknow, India

Rowe R K and Poulos H G 1979 A method for predicting the effect of piles on slope behaviour. Proc. $3^{\text {rd }}$ Intl. Conf. on Numerical Methods in Engineering, Vol. 3, Aachen

Schneider D, Kaitna R, Dietrich W, Hsu L, Huggel C and McArdell B 2011 Frictional behavior of granular gravel-ice mixtures in vertically rotating drum experiments and implications for rock-ice avalanches. Cold Regions Sci. Technol. 69(1): 70-90

Wang Y W 2000 The root extension rate of vetiver under different temperature treatments. Proc. Second Intern. Vetiver Conf. Thailand

Yoon P K 1994 Important biological considerations in use of vetiver grass hedge rows (VGHR) for slope protection and stabilization. Proc. Int. Conf. on Vegetation and Slopes, Oxford, England 